\title{
consulta@mgf.pt: um caso de comunicação médico-utente via correio electrónico
}

Philippe Botas, * Luiz Miguel Santiago, ** Liliana Constantino,* Paula Miranda*

\section{RESUMO}

Introdução: Novas abordagens de comunicação, como a utilização do correio electrónico, podem complementar a consulta de Medicina Geral e Familiar.

Descrição do caso: Mulher de 28 anos, pouco frequentadora de consultas no centro de saúde, tem, em consulta oportunista, diagnóstico de depressão, com baixa auto-estima e fraco suporte familiar, em situação de crise. O plano terapêutico, discutido com a utente, implicou a rejeição, pela paciente, da opção farmacológica e adesão a processo de introspecção orientado, com recurso ao correio electrónico para comunicação com o médico de família, após explicação do processo. Verificou-se sucesso das estratégias de coping desenvolvidas, com resolução progressiva dos sintomas depressivos em 4 meses.

Comentário: A utilidade do correio electrónico na comunicação com a utente, promovendo a adesão ao plano terapêutico, a sua capacitação e o reforço da relação médico-doente, numa perspectiva de prevenção quaternária, foi verificada com boa adaptação aos tempos e necessidades da paciente, sem sobrecarga para o médico.

Palavras-chave: Correio Electrónico; Relação Médico-Doente; Depressão.

egundo a definição Europeia de Medicina Geral e Familiar (MGF), as características desta disciplina estão inter-relacionadas e agrupam-se em seis categorias independentes de competências nucleares do Especialista em Medicina Geral e Familiar (EMGF). ${ }^{1}$ Ao reflectir sobre os aspectos chave da disciplina de MGF, compreende-se a importância da consulta como pilar central da prática clínica. «A consulta é a principal e a mais complexa actividade do médico de família e é a partir dela que se elabora o restante edifício da sua actividade profissional». ${ }^{2}$

Os avanços tecnológicos, que aparecem a um ritmo frenético, promovem modificações dinâmicas na actividade médica em geral e mesmo da prática clínica diária. O papel do EMGF adapta-se ao papel do utente, ao papel dos colegas de trabalho, às necessidades da comunidade e aos recursos existentes. Novas realidades permitem, e muitas vezes exigem, uma modificação do método de trabalho, destacando-se a informatização de registos e o fácil acesso a conhecimento através da internet.

*MD, Interno(a) de Medicina Geral e Familiar, Centro de Saúde de Eiras. **MD PhD, Assistente Graduado Sénior de Medicina Geral e Familiar, Centro de Saúde de Eiras
Aspectos negativos e positivos são relatados quanto ao advir desta nova realidade. O EMGF deve ter uma atitude crítica e tolerante, considerando novos instrumentos que o auxiliem na concretização das competências que definem a sua actividade. O desenvolvimento tecnológico não é incompatível com os direitos e deveres intemporais inerentes à profissão. Pelo contrário, a capacidade de acompanhar os avanços tecnológicos, avaliar criticamente e percepcionar que utilidade poderão ter para a actividade profissional, é essencial para uma melhoria da qualidade da actividade do médico, quer em seu benefício quer em benefício do utente.

O livro «A consulta em 7 passos» delineia um guia estrutural e contextual para a realização de consultas em MGF. $^{3}$ Os autores destacam a utilidade sugestiva das novas tecnologias da informação e comunicação, quer na óptica do raciocínio clínico e da decisão médica, quer na óptica do apoio e da capacitação do utente. ${ }^{3}$

A utilização do correio electrónico na comunicação médico-doente é fundamentada por normas de orientação clínica, ${ }^{4,5}$ que estabelecem recomendações para uma comunicação adequada, sustentada em aspectos éticos que devem ser ponderados na prática clínica. As vantagens inerentes à comunicação via endereço electrónico 
são contrabalançadas com desvantagens que não devem ser descuradas e que se relacionam predominantemente com questões de garantia da segurança e privacidade, de acessibilidade e de gestão da actividade clínica.-7

Em Portugal, e em particular no âmbito da MGF, a utilização do correio electrónico, como meio de comunicação complementar à consulta presencial, começa a ser adoptada com maior frequência. ${ }^{7-9}$

O caso clínico aqui relatado evidencia que, em casos seleccionados, o recurso a outros meios de comunicação, neste caso específico o correio electrónico, pode contribuir positivamente na actividade do EMGF. A comunicação médico-doente estabelecida via endereço electrónico revelou-se um importante instrumento na abordagem preventiva quaternária, definida pelaWONCA como «a detecção de indivíduos em risco de tratamento excessivo para os proteger de novas intervenções médicas inapropriadas e sugerir-lhes alternativas eticamente aceitáveis». ${ }^{10,11}$

\section{DESCRIÇ̃̃O DO CASO}

Identificação, antecedentes e caracterização familiar

L.L., sexo feminino, 28 anos, solteira, raça caucasóide, natural e residente em Coimbra, com $9 .^{\circ}$ ano de escolaridade e auxiliar de acção médica.

Antecedentes ginecológicos de menarca aos 13 anos com interlúnios de 25 dias e cataménios de 5 dias. Refere a toma irregular de contraceptivos orais, por esquecimento. Presentemente, a realizar contracepção hormonal oral. Nega utilização de outros métodos contraceptivos, à excepção de métodos barreira. Gesta I Para I (2008, parto eutócico sem complicações, às 39 semanas de gestação sem intercorrências). Para além da contracepção hormonal oral, toma diazepam $10 \mathrm{mg}$, ao deitar. Em relação a hábitos pessoais refere tabagismo (16 UMA) e nega hábitos etílicos ou toxicómanos. Destaca que realiza uma alimentação pouco equilibrada e escassa actividade física, que atribui em parte ao trabalho por turnos que a profissão exige. $O$ calendário vacinal está actualizado.

Escassas consultas na unidade de saúde em anos anteriores a 2011, com apenas duas consultas em 2010, por sinusite crónica/aguda. Sem registo em processo de outros problemas activos/inactivos.

Em relação aos antecedentes familiares, a utente faz referência ao diagnóstico de diabetes tipo 2 no avô pa- terno, no pai e em dois tios paternos. O pai já sofreu três episódios de acidente vascular cerebral (AVC), com 52 anos de idade. $\mathrm{O}$ avô paterno faleceu de enfarte agudo do miocárdio (EAM), com 82 anos, e a avó paterna faleceu com 69 anos, em sequência de AVC.

Ambiente familiar definido por família monoparental (vive com o filho de 3 anos), de classe média. A figura 1 mostra o genograma familiar, com representação de antecedentes pessoais e familiares, e com psicofigura de Mitchell - completado com dados colhidos durante as consultas realizadas.

\section{EPISÓDIOS DE ATENDIMENTO DESDE A PRIMEIRA CONSULTA COM A UTENTE \\ Consulta em 27 de Abril de 2011 (centro de saúde)}

Recorre ao centro de saúde da área de residência em regime de consulta aberta solicitando preenchimento de declaração para efeitos de pré-requisito tipo B, pois pretende realizar provas de ingresso em curso de enfermagem. Também traz carta relativa a episódio de urgência hospitalar por traumatismo do tornozelo e pé direitos, com lesão de tecidos moles.

Durante a consulta, a utente revelou alguns problemas familiares e fragilidade emocional, com choro fácil. Refere que tem períodos de tristeza e isolamento, sintomas que se têm agravado recentemente, acompanhados de falta de prazer nas coisas habituais da sua vida. Relata que teve um relacionamento há três anos, que considerava estável, mas o seu parceiro abandonou-a, sem grandes explicações, durante a fase inicial da gravidez e foi viver com outra mulher. Desde então, tentou abordar o ex-companheiro, mas este não se mostrou receptivo, na sua opinião por manipulação da actual companheira. O ex-companheiro nunca conheceu o filho e não manifesta esse interesse. Este episódio também teve marcas no relacionamento com os pais, pois estes nunca aceitaram a separação, de tal forma que a relação que tinha com a mãe, já anteriormente pouco harmoniosa, ficou mais conflituosa. Por esse motivo, decidiu sair de casa dos pais, vivendo há dois anos com o filho, em casa alugada.

Procedeu-se à colheita de dados para completar os registos do processo, através da anamnese e exame objectivo. Ao exame físico apresentava um IMC de 34 $\mathrm{kg} / \mathrm{m}^{2}$. A pressão arterial e a frequência cardíaca eram de 108/66 mmHg e 64 bpm, respectivamente. Na aus- 


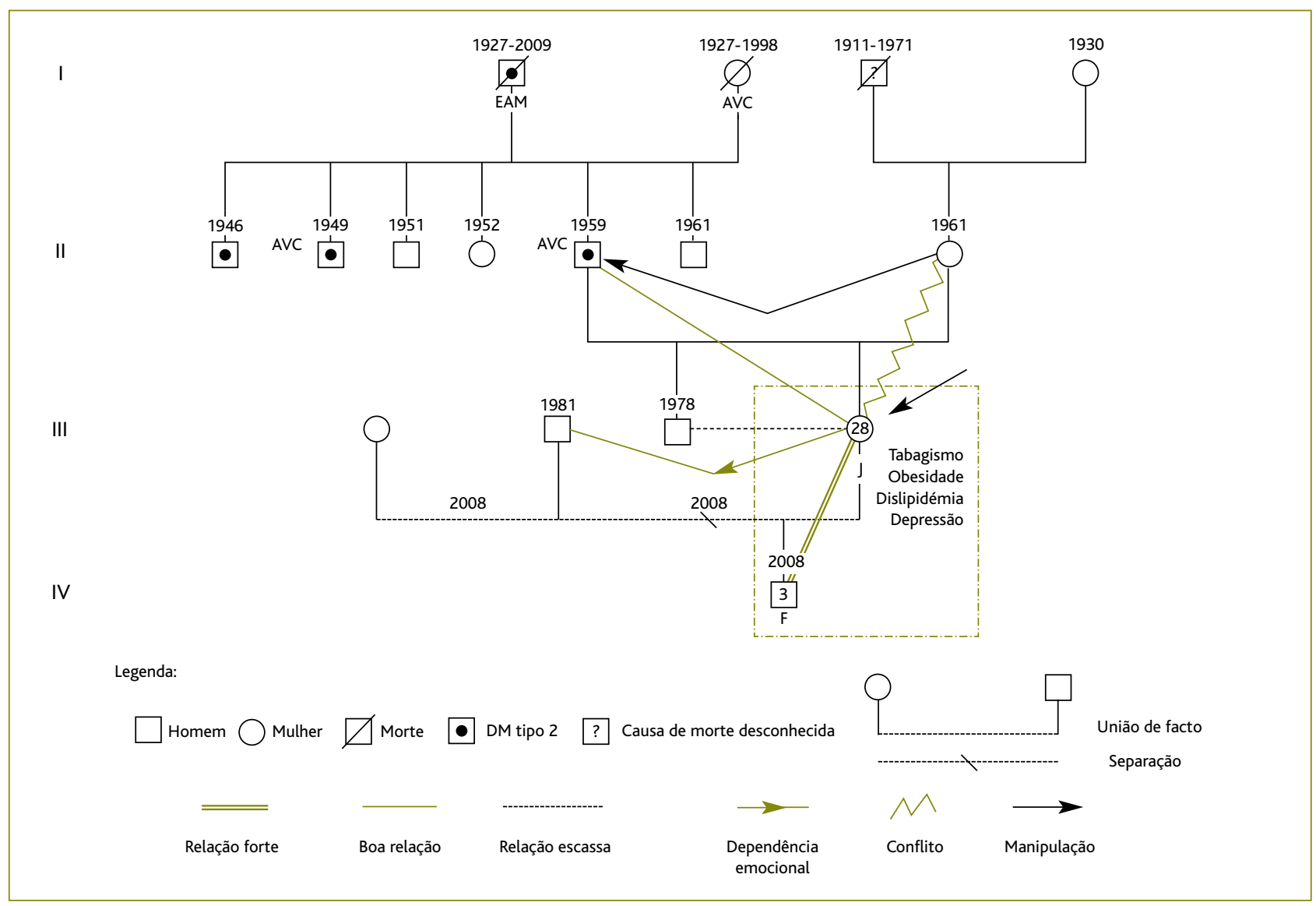

Figura 1. Genograma e Psicofigura de Mitchell (Família L, 8 de Agosto de 2011).

cultação cardíaca era aparente um sopro sistólico no foco mitral de grau I/VI. O exame do pé direito revelou um pequeno hematoma em regressão e dor ligeira à palpação do bordo externo, sem limitações da marcha e dos movimentos. Sem outras alterações no exame físico realizado. Exame ginecológico e citologia do colo uterino realizados pela última vez há três anos. No momento da consulta em fase menstrual, pelo que se agendou esta avaliação para consulta procedente.

Durante a entrevista, revelou um humor deprimido, acompanhado de labilidade emocional, baixa auto-estima, desânimo em relação ao futuro e baixa tolerância ao stress e ao fracasso. Sem objectivos de vida concretos, com expectativas que se centram na possibilidade do ex-companheiro regressar. Segundo L.L. este pensamento é a base da sua vida, constituindo um conflito intrínseco não resolvido («o meu filho faz-me lem- brar dele [ex-companheiro]. É muito parecido com ele, até na maneira de ser» [sic]; «se eu conseguisse falar com ele [ex-companheiro], podia ser que conseguisse que pelo menos visitasse o filho" [sic]).

A orientação integrada desta situação consistiu na elaboração de um plano conjunto com a utente, com aconselhamento terapêutico e discussão de diferentes abordagens possíveis, entre as quais a farmacológica que se colocou em comparação com as restantes. Rejeitou a necessidade de terapêutica farmacológica ou de consulta com psicóloga, afirmando «quero tentar com a vossa ajuda» (sic). Nesta perspectiva, aconselhou-se a reflexão sobre a conversa na consulta e sobre os motivos causadores destes sentimentos, sugerindo a escrita dos mesmos, principalmente em períodos de maior fragilidade emocional. Se desejasse partilhar os textos, poderia optar por enviar essas reflexões via correio electrónico. 
O plano incluiu o pedido de análises de sangue e de urina consideradas necessárias, electrocardiograma, assim como conselhos práticos para alteração dos hábitos alimentares e incentivo à realização de actividade física regular, discutindo de que modo se poderiam adaptar estas modificações ao estilo de vida da utente. Agendou-se consulta de planeamento familiar para o dia 2 de Maio.

Na figura 2 está representada a avaliação pela escala de readaptação social de Holmes e Rahe, demonstrando situações de crise, incluindo os acontecimentos significativos no presente.

\section{Consulta em 2 de Maio de 2011 (centro de saúde)}

Comparece à consulta programada com o resultado de análises. Ainda não realizou o ECG. Refere coágulos sanguíneos durante a menstruação, negando menorragias ou outros sintomas/sinais de foro ginecológico. Dos resultados analíticos destaca-se uma dislipidémia com valor de índice aterogénico de 5,2. Na reavaliação cardíaca por auscultação, não foram aparentes sopros. Realizado exame ginecológico com citologia do colo uterino. Detectou-se leucorreia, pelo que se procedeu

\begin{tabular}{|c|l|c|}
\hline $\mathbf{N} .^{\circ}$ & ACONTECIMENTO & Valor Médio \\
\hline 3 & Separação conjugal & 65 \\
\hline 16 & Mudança de situação económica & 38 \\
\hline 27 & Início ou fim de escolaridade & 26 \\
\hline 28 & Mudança nas condições de vida & 25 \\
\hline 32 & Mudança de residência & \\
\hline 39 & Mudança no n. ${ }^{\circ}$ de reuniões familiares & 15 \\
\hline & \multicolumn{2}{|c}{} \\
\hline 42 & Natal & 12 \\
\hline & \multicolumn{2}{|c}{} \\
\hline & \multicolumn{2}{|c}{} \\
\hline
\end{tabular}

Figura 2. Escala de readaptação social de Holmes e Rahe, para unidade de crise, em 27/04/2011 (adaptado de Caeiro, RT). ${ }^{12}$ à colheita de amostra para estudo bacteriológico e micológico. Procedeu-se ao reforço oportunista de hábitos higieno-dietéticos saudáveis.

Refere que reflectiu sobre a última consulta, mas que não teve tempo para escrever. Agora já define melhor os sentimentos: mantém mágoa de ex-companheiro «não contactar com o filho» (sic); tem esperanças que no futuro fiquem mais próximos. Quando questionada sobre a probabilidade de tal acontecer, perante os factos reais, o discurso torna-se menos optimista, transferindo a culpa para a actual parceira do seu ex-companheiro. Apresenta um discurso mais crítico, analisando de modo mais racional a sua situação pessoal e familiar, mas mantém e perspectiva objectivos de vida em torno da possibilidade de reconciliação conjugal: «Se conseguisse falar com ele!» (sic).

O aconselhamento volta a incidir na importância de reflectir sobre os seus sentimentos, sugerindo-se a escrita como auxílio nesta tarefa pessoal. Estabelece-se um compromisso de que a próxima consulta será por sua iniciativa e informamos que se for detectada alguma anomalia nos restantes exames, será contactada.

\section{7 de Maio 2011 (consulta@mgf.pt)}

Recebido correio electrónico da utente. Denuncia uma maior reflexão em relação à situação, revelando fragilidades a abordar:

«Tenho pensado muito na minha vida passada e presente. $\mathrm{E}$ aos poucos descobri que durante estes anos vivia na ilusão que o amor do passado um dia voltasse. (...) Pensava que se fosse atrás do que ficou mal resolvido conseguisse ter mais felicidade por juntar o pai e o filho. (...) só queria ter alguém que me amasse a mim e ao meu filho de verdade. (...) Gostava de ter uma borracha para apagar tudo o que eu passei, mas eu não o consigo esquecer (...) como posso eu ser feliz se a minha ferida ainda me dói, como é possível eu saber que ele não quer nada comigo (...) dói tanto, como faço para acabar com essa dor ou até esquecê-lo.» (sic)

\section{A nossa resposta:}

«Suponha que alguém lhe mandou este $e$-mail, o que lhe dizia? Releia e reflicta sobre o que sente.» (sic) 


\section{8 de Junho 2011 (consulta@mgf.pt)}

«Tenho andado muito nervosa... pois fiz o exame dos maiores de 23 para entrar para a faculdade de enfermagem... Andei sob pressão pois os meus pais diziam que me ajudavam em ficar com o meu filho, mas na verdade foi tudo ao contrário...». (sic)

\section{A nossa resposta:}

«Se precisar de falar, esteja à vontade». (sic)

\section{9 de Julho 2011 (consulta@mgf.pt)}

«Desculpe o incómodo, mas precisava falar com alguém... chumbei no exame com 8.15 , sinto que sou um fracasso (...) quem nasce sem sorte, morre sem ela (...) e essa é a minha vida. Quando era criança e adolescente, era e sou muito sonhadora... sonhava com uma vida estável linda, uma família unida, um marido impecável (...) casar e ter filhos. Tudo o que uma pessoa sonha para a vida. E o que foi que eu tive... sofrimento, dor, mágoa, solidão, tudo o que eu não queria. Quanto mais eu luto para ser alguém feliz, ter uma vida estável, é quando mais depressa tudo desaba (...) Tento, tento e só levo cabeçadas. Talvez seja uma forma de aprender com a vida." (sic)

\section{A nossa resposta:}

«O que consigo perceber é que o grande objectivo era o curso. Mas seria o único? Para construir um objectivo é preciso criar submetas. Estariam reunidas as condições para o sucesso no exame? Com isto refiro-me a Tempo, Relacionamentos, Família. Para o sucesso devemos construir o caminho que o permita. Prender-se no que corre mal, poderá fazer tudo correr ou parecer correr pior? Certo?» (sic)

\section{3 de Julho 2011 (consulta@mgf.pt)}

A resposta a este correio electrónico permitiu perceber outros dados sobre a dinâmica familiar.

«O exame foi tudo muito em cima do tempo e sem noção alguma do que poderia aparecer. (...) já tive mais apoio da parte do meu pai, em que conversávamos muito, agora tudo o que digo passa ao lado... com a mãe nunca tive um relacionamento bom e desde os meus quinze anos ficou pior... houve uma pessoa da minha família que tentou abusar de mim, quando contei à minha mãe ela não acreditou em mim (...) ela nunca me apoiou em nada, só sabe dizer que eu não presto entre outras coisas... põe o meu pai contra mim... enfim luto pela minha vida sozinha... se eu tivesse entrado na faculdade seria um pouco diferente... pois dava-me mais luta para não depender tanto deles.» (sic)

Também se verifica a referência a objectivos futuros:

«Eu sei que ele (ex-companheiro) não vale nada, mas não deixa de ser o pai do meu filho (...) ele é que me demonstrou o que era realmente o amor e ser amada. Agora só quero ter uma nova vida e isso inclui o meu futuro profissional e o meu filho. O resto, enfim, tento pôr numa caixa para enterrar, mas que seja tudo junto...» (sic).

$\mathrm{Na}$ abordagem posterior, enviou-se um correio electrónico a sugerir a leitura de todo o diálogo desde a primeira mensagem.

\section{Consulta em 8 de Agosto de 2011 (centro de saúde)}

Comparece a consulta não programada, manifestando interesse em colocar implante hormonal. Determinou-se o grau de conhecimento sobre os diferentes métodos contraceptivos, reforçando esse conhecimento, ao que manteve a opção pelo implante.

Naturalmente, abordaram-se as questões psicológicas e familiares. Apresenta uma mímica facial expressiva, sorrindo frequentemente, o que é concordante com um humor estável, contrastando com o carácter depressivo detectado nas consultas anteriores. Revela uma visão mais realista da vida. Releu todas as mensagens de correio electrónico e partilhou com uma amiga, afirmando que esta reflexão a tem ajudado muito. Tem um grupo de amigos recente que a tem ajudado, quer por partilha de sentimentos e experiências, quer na vivência social. Também refere que jánão sentenecessidade de tomar diazepam. Apresentaum discurso optimista e uma postura mais calma, revelando uma melhor reflexão sobre si mesma e satisfação pelo momento que vive. Persiste a relação conflituosa com os pais, sendo de momento a situação que a desmotiva mais, revelando mágoa pelas atitudes destes. As estratégias de coping desenvolvidas têm revelado efeitos positivos, com resolução progressiva dos sintomas depressivos: «Os pontos negativos dão força para seguir em frente» (sic). 


\section{COMENTÁRIO}

Como referido na introdução, a utilização do correio electrónico na comunicação médico-doente é alvo de orientações específicas que pretendem gerir de forma equilibrada a controvérsia que emerge com este instrumento de apoio à actividade clínica. ${ }^{4,5}$ A utilização do correio electrónico está dependente de um acordo mútuo entre o médico e o utente, no qual se definem o conteúdo das mensagens, o tempo de resposta e quem vai ler as mensagens, preservando a privacidade. ${ }^{4,5}$ Esta abordagem corresponde a um plano que assegura a continuidade de cuidados e deve ser escrita no registo clínico.

O caso descrito ilustra a utilidade do correio electrónico na comunicação com utentes, em casos seleccionados. O estudo realizado por Christensen H. et al., ${ }^{13}$ na Austrália, incluiu indivíduos com depressão e idades compreendidas entre os 18 e 52 anos, com o objectivo de avaliar a utilidade das abordagens cognitiva comportamental e educacional via internet. Os investigadores relataram resultados positivos associados a estas intervenções.

Em muitas consultas percebemos que o utente tem necessidade de falar e esse pode ser o plano terapêutico mais efectivo. Noutras consultas, percebemos que a pessoa tem dificuldade em verbalizar acontecimentos e sentimentos. Em ambos os casos o tempo de consulta que o EMGF dispõe, pode não ser compatível com as necessidades do utente. O correio electrónico é um meio de comunicação complementar com evidentes vantagens e a sua utilização na prática clínica em MGF começa a ser divulgada em Portugal como um importante instrumento de gestão do ficheiro de utentes e de apoio da consulta, compatível com as características da especialidade. ${ }^{7-9}$ Um estudo realizado numa USF em Portugal, relativa à utilização do correio electrónico na comunicação com os utentes, obteve resultados comparáveis a outras investigações noutros países, destacando que numa maior percentagem de casos os utentes abordam um único assunto por mensagem. ${ }^{8}$

A relevância da utilização deste instrumento de comunicação, neste caso, é caracterizada pelos seguintes aspectos práticos: utente de faixa etária jovem; pouco frequentadora de consultas na unidade de saúde; reforço da relação de confiança e percepção pela utente da disponibilidade para atendimento; adesão ao plano de cuidados delineado, capacitando e envolvendo a utente na construção do plano segundo as suas necessidades; gestão do tempo de consulta.

As duas primeiras consultas foram realizadas com um intervalo de uma semana, o que, numa situação de utente com escasso historial de consultas, pode representar uma abordagem vantajosa, determinando o grau de motivação, reforçando a relação médico-doente e minimizando a probabilidade de perder o seguimento. O recurso ao correio electrónico revelou-se bastante útil como complemento da consulta, o que foi verbalizado pela utente, sem comprometer a relação estabelecida, antes pelo contrário. Também se revelou um elemento fundamental no plano terapêutico.

O caso descrito demonstra a utilidade atribuída ao correio electrónico na perspectiva de capacitar a utente e permitir um investimento sustentável por parte do médico, sem necessidade de optar pela «medicalização», logo na primeira abordagem. Estas considerações vão de encontro com o emergir do conceito de prevenção quaternária. ${ }^{11,14}$ Actualmente, a prescrição farmacológica assume um papel primordial na prática clínica. Muitas vezes não constitui a abordagem mais indicada, mas a mais fácil e imediata para o médico e a mais aceite pelo utente. Esta circunstância deve ser alvo de uma consciencialização da comunidade médica, alertando para a importância de uma abordagem integrada e personalizada. Aideia de que o medicamento é sempre a solução é errónea. Quem sofre transfere as suas queixas a alguém que elaborará um raciocínio diagnóstico, passando o sofredor a ter um papel passivo perante as queixas e esperando que na receita esteja lá, não o que pode aliviar as suas queixas ou a doença que o médico encontrou, mas o necessário para a melhoria da sua saúde. ${ }^{15}$ Perante o diagnóstico clínico de perturbação depressiva, a opção pela prescrição farmacológica será a adoptada com maior frequência. Contudo, outras abordagens possíveis são evidentes, não sendo equacionadas tão rotineiramente, denunciando uma actividade clínica que, cada vez mais, se rege por normas, muitas vezes no campo da medicina defensiva.

O desenrolar do caso clínico descrito foi marcado pela elaboração de um plano terapêutico conjunto, competindo ao médico capacitar a utente para gerir a sua situação. O saber ouvir foi primordial para a abordagem deste caso, evitando uma atitude paternalista que frequentemente culmina na prescrição farmacológica e transferência de responsabilidade pelo pa- 
ciente. Mais do que rotular com um diagnóstico, procurou-se ajudar a utente a compreender os seus sentimentos, e aos poucos desenvolver estratégias de coping e delinear objectivos concretos. Este é o ponto forte do caso apresentado. Perante as alternativas colocadas, a escolha foi da utente, compreendendo-se que a sua responsabilização pela mudança da dinâmica mental e da sua situação beneficiou do recurso ao correio electrónico como meio de comunicação. Esta abordagem adaptou-se aos tempos e necessidades da paciente, reforçando a relação de confiança com o médico, que soube perceber a sua agenda de problemas. ${ }^{16}$

\section{REFERÊNCIAS BIBLIOGRÁFICAS}

1. Allen J, Gay B, Crebolder H, Heyrman J, Svab I, Ram P. A definição europeia de Medicina Geral e Familiar (Clínica Geral/Medicina Familiar). Rev Port Clin Geral 2005 Set-Out; 21 (5): 511-6.

2. Ramos V. A consulta em 7 passos. A consulta - pilar central da medicina geral e familiar. Lisboa:VFBM Comunicação; 2008.

3. Ramos V. A consulta em 7 passos. Instrumentos / ferramentas de apoio à consulta. Lisboa:VFBM Comunicação; 2008.

4. Kane B, Sands DZ. Guidelines for the clinical use of electronic mail with patients. J Am Med Inform Assoc. 1998 Jan- Feb; 5 (1): 104-11.

5. Canadian Medical Association. Physician guidelines for online communication with patients. Ottawa: Canadian Medical Association; 2005. Disponível em: http://policybase.cma.ca/dbtw-wpd/PolicyPDF/PD05-03.pdf [acedido em 02/02/2012].

6. Car J, Sheikh A. Email consultations in health care: 2 - acceptability and safe application. BMJ 2004 Aug 21; 329 (7463): 439-42.

7. Pinhão R, Calisto $M$, Pimentel MA, Fernandes R. Implementação da comunicação médico-doente via endereço electrónico na consulta de MGF. Rev Port Clin Ger- al 2009 Nov-Dez; 25 (6): 634-8.

8. Ponte C. A utilização do correio electrónico na comunicação com os utentes da USF Porta do Sol. Rev Port Clin Geral 2011 Mai-Jun; 27 (3): 274-80.

9. Granja M. O uso de e-mail na comunicação com o médico de família: catorze meses de experiência. Rev Port Clin Geral 2009 Nov-Dez; 25 (6): 639-46.

10. Bentzen N, editor. WONCA Dictionary of General/Family Practice. Wonca International Classification Committee: Copenhagen; 2003.

11. Melo M.A prevenção quaternária contra os excessos da medicina. Rev Port Clin Geral 2007 Mai-Jun; 23 (3): 289-93.

12. Caeiro RT. Registos clínicos em Medicina Familiar. Lisboa: Instituto de Clínica Geral da Zona Sul; 1991.

13. Christensen H, Griffiths KM, Jorm AF. Delivering interventions for depression by using the internet: randomized controlled trial. BMJ 2004 Jan 31; 328 (7434): 265.

14. UEMO position on Disease Mongering / Quaternary Prevention. 2008. Disponível em: http://www.uemo.eu/uemo-policy/123-uemo-position-on-diseasemongering — quaternary-prevention.html [acedido em 18/08/2011].

15. Santiago LM, Neves C, Constantino L.A relação dos doentes com a receita médica - Um Estudo Observacional em Populações Urbanas no Centro de Portugal. Acta Med Port 2010 Set-Out; 23 (5): 755-60.

16. Santiago LM, Neves C, Constantino L, Leon-Rodríguez E. La agenda de problemas del paciente: por que ván a consulta y qué quieren saber sobre sus enfermedades o dolencias: un estudio de observación en poblaciones urbanas del Centro de Portugal en el àmbito de Medicina General y Familiar. Aten Primaria 2009 nov; 41 (11): 654-5.

\author{
ENDEREÇO PARA CORRESPONDÊNCIA \\ Philippe José Couto Botas \\ Rua das Arroteias, N. ${ }^{1}$ \\ 3105-303 Redinha \\ E-mail: philippe_botas@hotmail.com
}

Recebido em 31/08/2011

Aceite para publicação em 22/11/2011

\section{ABSTRACT}

\section{consulta@mgf.pt: A CASE REPORT OF DOCTOR-PATIENT COMMUNICATION USING E-MAIL}

Introduction: New methods of communication, such as electronic mail, can complement the General practice/Family medicine consultation.

The case: A 28 year old woman who rarely consulted with her family doctor was diagnosed with depression and low self-esteem in a consultation requested for other reasons. She had low family support and was found to be in crisis. The patient rejected the offer of drug treatment. The treatment proposed consisted of introspection-oriented work through written texts sent by email to her family doctor. Coping was enhanced with progressive resolution of the depressive symptoms noted over a four month period.

Commentary: E-mail communication with the patient was found to promote adherence to treatment, patient empowerment, and the doctor-patient relationship. This met the patient's needs in a timely way without extra work for the doctor.

Keywords: Electronic Mail; Doctor-Patient Relationship; Depression. 